\title{
QUIÉN ES QUIÉN EN EL ESPACIO PÚBLICO: POLÍTICA E IDENTIDAD EN H. ARENDT
}

\author{
María José López Merino ${ }^{1}$
}

\section{Resumen/Abstract}

En lo que sigue presentamos el concepto de identidad del quién, que Arendt expone en su obra The Human Condition, ligado a la noción de acción política. Presentamos este concepto ligado a tres anomalías que registra la lectura de Arendt: la primera vinculada con la misma noción de política que explora la autora, la segunda vinculada a su posición como pensadora anti-metafísica, y la tercera relacionada ya no con sus ideas sino con su praxis como pensadora: las actividades que la sitúan en espacio público como un quién que tiene algo que decir, específicamente, en dos momentos peculiares en su escritura: Los orígenes del Totalitarismo y Rahel Varnhagen. La vida de unajudia.

Palabras claves: identidad, quién, acción, narración, espacio público

\section{WHO IS WHO IN THE PUBLIC SPACE: POLICITY AND IDENTI-} TY IN H. ARENDT

This article presents the concept of the identity of the 'who', exposed by Arendt in her book The Human Condition, linked to the notion of political action. We introduce this concept related to three anomalies that appear in Arendt's reading: the first associated to the very notion of politics that she explores, the second linked to her position as an antimetaphysical thinker, and the third related not with her ideas but with her praxis as thinker: her activities in the public space like a 'who' that has something to say, specifically, in two peculiar moments in her production: Origins of Totalitarianism and Rahel Varnghagen, the Life of a Jewess.

Keyword: identity, who, action, narration, public space

1 Chilena, Departamento de Filosofía de la Facultad de Filosofía y Humanidades de la Universidad de Chile. Este artículo es parte del proyecto Fondecyt Regular n 1140200 en el que participa como coinvestigadora. 
El capítulo cinco de The Human Condition de H. Arendt en su parágrafo 24 , se inicia con algunas reflexiones acerca de la identidad de los agentes de la acción. La acción (action) entendida como praxis, estaría indisociablemente vinculada a un quién de la acción. En este sentido, nos advierte la autora, “....el acto primordial y específicamente humano (acción y discurso) debe contener al mismo tiempo la respuesta a la pregunta planteada a todo recién llegado: «¿Quién eres tú?" (Arendt, 1993: 202). Así, parece que lo primero que podemos decir de la noción de "acción política" que comienza a dibujar la autora, es que nos permite saber quién es quién.

Lo que aquí está en juego en este crucial capítulo, es un concepto de identidad individual asociado a la política, al menos, anómalo en la tradición del pensamiento político-filosófico. Nombremos algunas caras de esta anomalía que nos proponemos explorar en el presente artículo: en primer lugar la política es comprendida en este libro y en especial en este capítulo, como un conjunto de prácticas que realizan individuos singulares, relacionados pero siempre individualizables. Esto evidentemente nada tiene que ver con la reflexión sobre las instituciones y su origen, o su legitimidad, o sobre el quehacer de fuerzas sociales colectivas, preguntas claves en la tradición del pensamiento político y que no pueden ser respondidas desde la reflexión acerca de la identidad de los agentes. En este nivel la anomalía proviene del concepto mismo de lo político desarrollado por la autora, vinculado a una peculiar noción de acción y de individualidad, o mejor individualidades, ya que siempre ésta se da en plural.

Otra cara de esta anomalía: Arendt se identifica como una pensadora antimetafísca, o como parte de “...aquellos que están empeñados conscientemente en destruir a la metafísica” (Arendt, 1981:212), una filósofa del martillo podríamos agregar nosotros, y sin embargo, reedita al parecer, un concepto de identidad individual. ¿Puede haber algo más metafísico que hablar de identidad, en este caso identidad individual? Anómala, en una pensadora política como es Arendt, resulta su constante preocupación por no perder el carácter único, la unicidad (uniqueness) de cada actor, que no se jugaría en la esfera privada ni intima, sino bajo la luz de lo público.

Por último, hay al menos una tercera anomalía, que no tiene que ver con las ideas que Arendt expone, sino con las prácticas que ella realiza en su propio itinerario intelectual y que la convierten, a veces a pesar de 
ella misma, en un quién ante los otros, una pensadora que opina y expone y se expone en el espacio público. Arendt, si uno mira su biografía y su obra, realiza un trabajo decidido de autoformación como pensadora, como intelectual y como filósofa ${ }^{2}$. No hay nada natural en su trayectoria pública, ya que tuvo casi todo en contra: mujer, judío-alemana, que se convierte en una académica e intelectual destacada en el medio norteamericano. En este punto, filosofía, espacio público, biografía e identidad, se entrelazan, marcando uno de los focos más atrayentes de la obra de Arendt: cuándo y cómo se convierte en filósofa. Cómo y con qué recursos y estrategia lo hace. Incluso más allá, cómo se mezclan filosofía, identidad y sobrevivencia, ya que la pensadora hace de su filosofía una verdadera tabla de salvación para las catástrofes políticas, sociales y personales que enfrenta. La propia Arendt en su vida, realiza una recreación constate de su identidad, lo que le permite aparecer ante otros con su propio quién, no siempre de manera pacífica, por cierto. A mi juicio, el quién que es la propia Arendt y el cómo ella se hace filósofa o más ampliamente, una pensadora, es uno de los centros gravitacionales del interés creciente que genera esta autora y que nos conecta de una manera directa o indirecta a todas con una pregunta central para quienes hemos hecho una vida vinculada al leer, enseñar, escribir, conversar de filosofía: ¿cuándo una mujer se vuelve, por fin, filósofa?

\section{Los quienes, la acción y el discurso}

La acción entendida como praxis, ya lo sabemos, es la actividad central en la geografía de las actividades prácticas que la autora alemana nos presenta en The Human Condition. No es una actividad cualquiera, a diferencia del trabajo (work), no tiene su fin fuera de ella en un resultado o producto, a diferencia de la mera labor (labor) no es una actividad movida por la necesidad ni mediada por la violencia.

La praxis, valga repetirlo una vez más, es una actividad que tiene sentido en sí misma. Esta nota distintiva nos lleva directamente al Capítulo VI de la Ética a Nicómaco, cuando Aristóteles distingue las dos actividades prácticas: praxis y poiesis. Siguiendo el modelo aristotélico esta praxis es presentada negativamente como una actividad no teorética, e improductiva ${ }^{3}$.

2 Conocidas son las reticencias de la propia Arendt a ser llamada filósofa. Ver la entrevista de Gunther Gaus a H. Arendt en https://www.youtube.com/watch?v=WDovm3A1wI 4

3 “...el proceso de actuar y hablar puede no dejar tras de sí resultados y productos finales” (207). 
Esta poiesis es para Arendt, como ya es para Aristóteles ${ }^{4} u n a$ actividad prepolítica (Arendt, 1993: 218), consistente en un cierto hacer práctico de acuerdo a fines, y siguiendo la ruta del camino ideado por la contemplación del modelo o de su plan a seguir. En cambio, la acción es en sí misma ajena a las imposiciones de los modelos previos ${ }^{5}$, porque aunque los actores puedan tener motivos y fines, la actividad misma, es decir, la acción no se define a partir de ellos.

Al mismo tiempo, la praxis es una actividad que se ha desvinculado ya de la naturaleza y del repetitivo ciclo de la sobrevivencia. La praxis no es labor, aquella que realiza el animal laborans como actividad práctica necesaria para el mantenimiento de la vida en su sentido más elemental. (Arendt, 1993: 109). Su tiempo es siempre cíclico, porque una vez que termina de 'mantener' la vida, debe comenzar de nuevo, y su lógica, es la repetición constante de este ciclo de la sobrevivencia: se labora para consumir lo necesario para la vida y una vez que se consume, el ciclo comienza otra vez (Arendt, 1993: 108).

Mientras los productos del trabajo se usan, los productos de la labor se consumen. Mientras la producción (poiesis) o el trabajo (work) van unidas al placer de crear, haciendo uso de la imaginación, la actividad laborante va unida inevitablemente a la dureza del quehacer de 'mantener la vida' (Arendt, 1993: 111) y no tiene más sentido, que la generación de las condiciones para la vida en su sentido más básico: la sobrevivencia.

Volviendo a la definición de praxis, quizás su significado más claro, surge de la identificación al menos parcial que realiza la autora entre acción y natalidad. Recordemos que la natalidad no es en Arendt un único concepto sino un conjunto o constelación de conceptos vinculados. En uno de sus sentidos 'natalidad' se identifica con la acción en su sentido más básico y olvidado: actuar es sobre todo hacer nacer, iniciar algo en el mundo que luego sigue su propia vida. Así, la anatomía de la acción, sólo queda delimitada positivamente en The Human Condition cuando de la mano de la autora, recuperamos éste su sentido original de iniciativa: actuar ya no es realizar, llevar a término, 'comportarse' en el sentido de realizar una conducta de

4 Especialmente en Aristóteles (2004) Libro I.

5 "Los motivos y objetivos, por puros y grandiosos que sean, nunca son únicos; al igual que las cualidades psicológicas, son típicos, característicos de diferentes clases de personas. La grandeza por tanto, o el significado específico de cada acto, sólo puede basarse en la propia realización ni en su motivación ni en su logro" (Arendt, 1993: 229). 
acuerdo a fines y metas, actuar es comenzar. ${ }^{6}$ Justamente gracias a que la acción es un puro comienzo es que de ella puede esperarse lo inesperado va a decir Arendt ${ }^{7}$. Así, la acción arendtiana al estar fuertemente identificada con la actividad de 'comenzar', se comprende como específicamente 'performativa', es decir, que encuentra en su propia realización su sentido. Se trata para Arendt de una “...insistencia (otra vez aristotélica) en los actos vivos y en la palabra hablada como los mayores logros de que son capaces los seres humanos" (Arendt, 1993: 229). Los ejemplos clásicos que da el propio Aristóteles de esta forma de actividad 'viva' o interpretativa son la actividad del ojo, en la que ver sólo significa 'estar viendo' y la actividad del flautista, o del actor, que se define por su propia performance, tal como nos explica la filósofa: “...en la interpretación del danzarín o del actor, el 'producto' es idéntico al propio acto interpretativo” (Arendt, 1993: 229) ${ }^{8}$. Este carácter interpretativo supone desde ya una improductividad definitiva y radical de la acción, que la convierte, en la más valiosa y al mismo tiempo “...la más fútil de las actividades humanas” (Arendt, 1993: 220), en tanto al desaparecer no deja prácticamente nada tras de sí.

De esta manera, al acercarnos más al capítulo $\mathrm{V}$ de The Human Condition, la referencia más evidente ya no es el libro VI de la Ética a Nicómaco, sino la Poética de Aristóteles y el modelo de la praxis como interpretación de los actores y los músicos (acción performativa) ejemplos que abundan también en el Aristóteles de La Politica Recordemos incluso hacia el final del parágrafo 25 del capítulo V, Arendt hace aparecer la imitación de la acción, mimesis praexos, y el arte del drama, como forma

6 ....el griego y el latín, a diferencia de las lenguas modernas, contienen dos palabras diferentes y sin embargo interrelacionadas para designar el verbo actuar. A los verbos griegos 'archein' (comenzar, guiar y finalmente gobernar) y 'prattein' (atravesar realizar, acabar) corresponden los verbos latinos agere (poner en movimiento, guiar) y 'gerere' (cuyo significado original es llevar) Parece como si cada acción estuviera dividida en dos partes, el comienzo, realizado por una sola persona, y el final, en que se unen muchas para 'llevar' y acabar la empresa aportando su ayuda." (...) "en ambos casos (el griego y el latín) la palabra que originalmente designaba sólo la segunda parte de la acción, su conclusión - prattein y gerere- pasó a ser la palabra aceptada para la acción en general, mientras que las que designaban el comienzo de la acción se especializaron en el significado, al menos en el lenguaje político. Archein pasó a querer decir principalmente gobernar y guiar cuando se usó de manera específica y agere significó guiar en vez de 'poner en movimiento"' (213).

7 "En la propia naturaleza del comienzo radica que se inicie algo nuevo que no puede esperarse de cualquier cosa que haya ocurrido antes. Este carácter de lo inicialmente inesperado (startling unexpectedness) es inherente a todos los comienzos y a todos los orígenes." (Arendt, 1993: 201).

8 Este carácter 'vivo' que no permite separar actividad y obra es también propia de la idea de 'existencia' del Dasein heideggeriano. 
interpretativa privilegiada, que hace patente el carácter "revelador de la acción”. Así concluye el parágrafo señalando que “... la cualidad específica y reveladora de la acción y del discurso, la implícita manifestación del agente y del orador, está tan indisolublemente ligada al flujo vivo de actuar y hablar que sólo puede representarse y reificarse mediante una especie de repetición, de imitación o mímesis, que según Aristóteles, prevalece en todas las artes aunque únicamente es apropiada de verdad al drama, cuyo mismo nombre (del griego 'dran', actuar) indica que la interpretación de una obra es una imitación de actuar" (Arendt, 1993: 211).

El arte interpretativo por excelencia que es el teatro, el drama representado, nos permite señalar otro de los rasgos que acompañan indefectiblemente a la acción: se trata de la actividad práctica que sólo ocurre entre y ante otros. Esto significa que la acción es siempre intersubjetiva, supone ya otros. Los supone además como espectadores-hermenéutas de la acción, como aquellos que la identifican y le ponen nombre a esa acción, abriendo un espacio entre los seres humanos, un espacio que los liga y los separa, directamente y sin la mediación de las cosas. En este sentido, y como nos advierte la autora: "La acción es la única actividad que se da entre los hombres sin mediación de cosas" (Arendt, 1993: 21-22).?

La acción supone ya este estar involucrado en una trama de acciones con otros, a través de lo que Arendt llama la condición de la pluralidad palabra que no alude solamente a la constatación de que existir para un ser humano es hacerlo ya en un horizonte donde existen otros ${ }^{10}$. Alude también al hecho de que esa originalidad de la experiencia de los "muchos"(polloi) como horizonte último de la política, hace surgir la posibilidad de la diversidad y el carácter único e irreductible de cada mirada y con ello de cada identidad. Pluralidad y unicidad van completamente unidos: se trata de la capacidad de ser y mostrarse diversos, que sólo surge entre y ante otros.

Desde esta perspectiva el fundamento de la política está en esa diversidad irreductible, en esa posibilidad de polémica y diferencia que no se reduce ni con el acuerdo ni con la amistad cívica sino, que al revés, se trata de una diversidad que supone y sustenta cualquier acuerdo y cualquier vínculo político entre los sujetos: en tanto sólo son posibles en un mundo donde no somos los mismos y donde la diferencia es en último término

9 Nos alejamos aquí rápidamente de Heidegger y su condición del Mitsein, un ser entre otros mediado cotidianamente justamente por nuestras relaciones con las cosas.

10 En palabras de la autora que "..son los hombres y no el hombre el que habita la tierra” (Arendt, 1993: 23). 
insuperable: "La pluralidad es la condición de la acción humana debido a que todos somos lo mismo, es decir, humanos, y por tanto nadie es igual a cualquier otro que haya vivido, viva o vivirá" (Arendt, 1993: 22).

Así, es esta pluralidad de hombres y mujeres actuando y hablando la que genera el espacio público, que para la autora no es ningún lugar previo ya fijado, sino el delgado espacio del 'entre' (in between) y de la diferencia, que caracteriza a la comunidad política en su inmediato sentido de poder aparecer y hacer juntos: "La polis propiamente hablando, no es la ciudadestado en su situación física; es la organización de la gente tal como surge de actuar y hablar juntos, y su verdadero espacio se extiende entre las personas que viven juntas para este propósito, sin importar dónde estén (...) Se trata del espacio de aparición en el más amplio sentido de la palabra, es decir, el espacio donde yo aparezco ante otros como otros aparecen ante mí, donde los hombres no existen meramente como otras cosas vivas e inanimadas, sino que hacen su aparición de manera explícita" (Arendt, 1993: 221).

De esta manera, la acción determina el centro de la actividad política y de su lugar, lugar que no es más que el espacio práctico donde la acción tiene lugar. La polis viva, realizada, no como institución ni como recuerdo, sino como actualidad, energeia, actividad pura, que en tanto tiene lugar, abre un espacio de aparición que es el espacio público, que permite que aparezca la identidad. En este sentido, nos advierte Arendt: "Mediante la acción y el discurso, los hombres muestran quiénes son, revelan activamente su única y personal identidad y hacen su aparición en el mundo humano" (Arendt, 1993: 203).

La ligazón entre acción e identidad del agente es tan decisiva que a la luz de este primero parágrafo del capítulo (24), aparece como una nota distintiva de la misma acción: "Sin la revelación del agente en el acto, la acción pierde su específico carácter y pasa a ser una forma de realización entre otras. En efecto, entonces no es menos medio para un fin que lo es la fabricación para producir un objeto." (Arendt, 1993: 204). Sin este carácter revelador, que enuncia a un quién completamente ligado a la praxis se degrada y se vuelve mera forma práctica de realización, producción, actividad práctica que concretiza un fin.

Ahora bien, Arendt nos propone una cierta vía negativa para acercarnos a esta identidad del agente: En primer lugar, el quién en el espacio público, es alguien que no es un qué: 'El descubrimiento de 'quién' en contradistinción al 'qué' es alguien -sus cualidades, dotes, talento y defectos que 
exhibe u oculta- está implícito en todo lo que ese alguien dice y hace." (Arendt, 1993: 203). En este sentido, nos advierte la autora: la identidad del agente(...)"Sólo puede ocultarse en completo silencio y perfecta pasividad, pero su revelación casi nunca puede realizarse como fin voluntario, como si uno poseyera y dispusiese de este 'quién' de la misma manera que puede hacerlo con sus cualidades". (Arendt, 1993: 203). En este punto y en el anterior, comienzan a aparecer las notas específicas de esta identidad: no se trata de la identidad de una cosa, o de un objeto, ni de un sujeto que se opone a un objeto. Menos aún es la identidad de una experiencia de "dominio de sí", de un sujeto soberano que mediante su voluntad, su acción productiva, se afana en ser y aparecer como alguien. Es decir de un 'quién' que se produce a sí mismo como un qué, como un producto de sí. Muy por el contrario, el quién, en la descripción arendtiana tiene su nudo en un fuera de sí de la experiencia del agente. El quién se construye justamente en lo que el agente no domina, en su punto ciego. Nos aclara Arendt: "...es más que probable que el 'quién', que se presenta tan claro e inconfundible a los demás, permanezca oculto para la propia persona, como el daimon de la religión griega que acompañaba a todo hombre a lo largo de su vida, siempre mirando desde atrás por encima del hombro del ser humano y por lo tanto sólo visible a los que éste encontraba de frente" (Arendt, 1993: 203). El quién como revelación surge así del punto ciego, de lo que Merleau-Ponty llamaba refiriéndose al propio cuerpo: la oscuridad de la sala, que hace posible la proyección de la película. Aquel punto de ceguera que construye la perspectiva y organiza así la mirada, ligando objeto percibido recorrido y cuerpo exploratorio (Merleau-Ponty, 2004, 108).

Aquí está el principal riesgo del quién y de su identidad, tal como la describe Arendt en estas páginas: se trata de un quién que se revela sin dominio, sin soberanía en el espacio público. En este sentido: "Aunque nadie sabe a quién revela cuando uno se descubre a sí mismo en la acción o la palabra, voluntariamente se ha de correr el riesgo de la revelación, y esto no pueden asumirlo ni el hacedor de buenas obras, que debe ocultar su yo y permanecer en completo anonimato, ni el delincuente, que ha de esconderse de los demás. Los dos son figuras solitarias" (Arendt, 1993: 204). Actuar es así, correr el riesgo de la revelación y de la compañía, mostrarse sin querer $\mathrm{y}$ en aquello que a veces no se quiere mostrar. Este es el precio que hay que pagar por actuar, aparecer y revelarse ante otros, dándoles una visión de un quién que no tenemos a nuestra disposición que no es un objeto ni una cosa nuestra o si quiera de nuestra conciencia.

Ahora bien, no es lo mismo a la hora de mostrar el quién las acciones 
que iniciamos y las palabras que decimos. Ya que las palabras tendrían una especial capacidad reveladora, de la distinción de cada uno, de la propia unicidad de la que ya hablábamos ${ }^{11}$.Tal como nos dice la autora: "Este descubrimiento de quién es alguien está implícito tanto en sus palabras como en sus actos; sin embargo, la afinidad entre discurso y revelación es mucho más próxima que entre acción y revelación” (Arendt, 1993: 202). Incluso más, la acción, praxis pura que no es realización sino más bien interpretación, requiere de los efectos aclaradores del discurso ${ }^{12}$.

Sin embargo, esta capacidad reveladora aleja al discurso (entendido como acción, action) de la comunicación. Sigue Arendt: "Ninguna otra realización humana requiere el discurso en la misma medida que la acción. En todas las demás, el discurso desempeña un papel subordinado, como medio de comunicación o simple acompañamiento de algo que también puedo realizarse en silencio. Cierto es que el discurso es útil en extremo como medio de comunicación e información, pero como tal podría reemplazarse por un lenguaje de signos, que tal vez se mostrara ser más útil y conveniente para transmitir ciertos significados, como en el caso de las matemáticas y otras disciplinas científicas o en ciertas formas de trabajo en equipo."(Arendt, 1993: 203) Fundamental la pista que da aquí Arendt: el discurso revelador del agente no coincide con el discurso como medio de comunicación. Así, la identidad no es un producto o un mensaje, enviado/trasmitido, codificado-decodificado en el espacio público. Revelar no es comunicar, todo lo contrario, el discurso si se lo desliga del quién que ya habíamos descrito en la acción, puede convertirse en un discurso que se limita a comunicar y ya no a revelar, puede dirigir un proceso de realización, perdiendo su intrínseco poder revelador, se convierte en mera charla (Arendt, 1993: 204).

Detrás de este peligro que acecha el delgado lazo que une acción, discurso y agente, y dándole sustento a este peligro, está el panorama de toda una cultura de la desaparición del quién que en gran medida es descrita por

11 "Si la acción como comienzo corresponde al hecho de nacer, si es la realización condición humana de la natalidad, el discurso corresponde al hecho de la distinción y es la realización de la condición humana de la pluralidad, es decir, de vivir como ser distinto y únicos entre iguales" (Arendt, 1993: 202).

12 En todo caso, sin el acompañamiento del discurso, la acción no sólo perdería su carácter revelador, sino también su sujeto, como si dijéramos; si en lugar de hombres de acción hubiera robots se lograría algo que, hablando humanamente por la palabra y, aunque su acto pueda captarse en su cruda apariencia física sin acompañamiento verbal, sólo se hace pertinente a través de la palabra hablada, en la que se identifica con el actor, anunciando lo que hace, lo que ha hecho y lo que intenta hacer" (Arendt, 1993: 202). 
Arendt especialmente en The Human Condition, pero también de manera importante en el epílogo de The Origins of Totalitarianism, como también en algunas de sus obras posteriores. No sólo el pensar dominador y jerárquico, antipolítico de cierto Platón y de cierto Heidegger, no sólo el desprecio por la acción y por la vida práctica que está en el origen de la filosofía griega, y luego, cristiana y finalmente moderna. Así como también, el miedo a la experiencia política y su pluralidad que estarían vigentes en nuestra cultura desde el juicio de Sócrates, sino también y de manera decisiva a mi juicio, el quehacer de una cultura social, que cristaliza en el capitalismo moderno como sistema productivo que organiza el trabajo, y la vida práctica en general, desdibujando las identidades de las singularidades que marca. La división del trabajo, la cultura de masas, los medios de comunicación, las técnicas y métodos de las ciencias sociales, son formas contemporáneas que profundizan en este desdibujamiento de los "quienes" y de su reemplazo por los 'nadie' o por los cualquiera' que aparecen en el ámbito social, como seres anónimos y desindividualizados en el largo proceso de lo que la autora llama "el ascenso de lo social" (Arendt, 1993:204-205).

\section{Los quienes y la destrucción de la metafísica}

Las reflexiones sobre la identidad del quién, que intentamos exponer en el punto anterior entran directamente en la disputa con una cierta metafísica frente a la cual, Arendt se declara en disputa. Lo dice abiertamente Arendt en el parágrafo 25, que ya veníamos comentando: "En el momento en que queremos decir quién es alguien, nuestro mismo vocabulario nos induce a decir qué es ese alguien; quedamos enredados en una descripción de cualidades que necesariamente ese alguien comparte con otros como él; comenzamos a describir un tipo o 'carácter' en el antiguo sentido de la palabra, con el resultado de que su específica unicidad se nos escapa" (Arendt, 1993: 205). Ya lo hemos dicho, esto significa, confundir el quién con un qué, tratar lo que deviene como si estuviera fijo, la experiencia como un conocimiento, lo que tiene existencia como algo que tiene esencia y puede ser descrito mediante una colección de notas o caracteres. Pero esta confusión parece ser endémica a nuestra tendencia a nombrar y describir. Y prosigue Arendt: se trata de "...la imposibilidad, como si dijéramos, de solidificar en palabras la esencia viva de la persona tal como se muestra en el flujo ${ }^{13}$ de acción y discurso, que tiene gran relación con la esfera de asuntos

13 Corregimos aquí la traducción castellana que traduce 'flux' por fusión cuando en realidad quiere decir flujo. 
humanos" (Arendt, 1993: 205). Estamos más bien ante una existencia abierta e instalada en el mundo y su propia experiencia no es más que la experiencia temporal que deviene, de manera insegura y frágil, como el río de Heráclito, en la experiencia del que está siendo. En este sentido nos aclara la autora, quizás para confundirnos definitivamente: "La cuestión estriba en que la manifestación del 'quien' acaece de la misma manera que las manifestaciones claramente no dignas de confianza de los antiguos oráculos que, según Heráclito, 'ni revelan ni ocultan con palabras, sino que dan signos manifiestos'. Éste es un factor básico en la también notoria inseguridad no sólo de todos los asuntos políticos, sino de todos los asuntos que se dan directamente entre hombres, sin la intermediaria, estabilizadora y solidificadora influencia de las cosas". (Arendt, 1996: 206). Nos topamos aquí con una aclaración decisiva: Como ya veíamos en el punto anterior, no se trata de decir lo que es el quién, sino de una revelación de ese quién en tanto cifra, enigma, en tanto lenguaje de lo que no se puede decir. Esta concepción heracliteana del signo que Arendt según la nota 7 del capítulo que analizamos, también identifica con la concepción de daimon socrático ${ }^{14}$ : lo que los otros ven, no es nada cierto ni claro, no es un significado como contraparte de un significante, ni un contenido ni un mensaje, sino es más bien la manifestación de algo que se manifiesta para seguir oculto.

Más allá de Arendt, no puedo evitar relacionar esta comprensión del discurso que dice el quién, como daimon, como signo oracular, con lo que Ronald Barthes dice acerca de la escritura: La escritura, a diferencia del habla, tiene un origen sacerdotal y criptográfico, no se trataba de comunicar y mantener o trasmitir conocimiento, sino más bien, de ponerlo a resguardo, cifrándolo en caracteres que sólo unos pocos pudieran descifrar. El signo escrito, a diferencia del signo hablado que es siempre actual, situacional, vinculado a la comunicación y sus urgencias, el signo escrito decíamos, habría sido creado para ocultar, para mantener el secreto y no para comunicar (Barthes y Campa, 1989).

Lo importante para nosotros en la lectura de la identidad en Arendt, es que se trata de destruir la identidad del sujeto-cosa, y sobreponerle la identidad de una agente-enigma. Que tiene una identidad no interior, no esencial, no permanente, expuesta al espacio público y tan frágil como la

14 En la nota 7, Arendt aclara: "Sócrates empleó la misma palabra que Heráclito, semainein (mostrar y dar signos), para la manifestación de su daimonion (Jenofonte, Memorabilia I., 1.2.4.) Si hemos de confiar en Jenofonte, Sócrates comparaba su daimonion con los oráculos e insistía en que ambos se usaran sólo para asuntos humanos, donde nada es cierto, y no para los problemas de las artes y oficios, donde todo se puede predecir" (Arendt, 1993: 267). 
acción y el discurso que la sustentan, una identidad que otros nombran y cuentan, pero que no se pueda identificar ni descomponer, es una identidad cifrada, un símbolo que se dice y se recrea sin deshacer el misterio que encierra, una identidad símbolo.

Queda a mi juicio bastante claro, hasta qué punto esta noción de identidad expuesta de The Human Condition, es parte de un ejercicio de desmontaje, confluyendo finalmente con el proyecto de destrucción de la metafísica y la recuperación de una identidad que no coincide nunca consigo misma, sino que guarda dentro de ella también su diferencia. El gran contraste de esta identidad que se revela como cifra, como enigma, como símbolo, aparece cuando la filósofa se refiere a la identidad divina. Recordemos que hay una cierta constancia en la crítica de Arendt al monoteísmo ${ }^{15}$ que se vincula muy directamente con la manera en que ella interpreta la tarea antimetafísica de su propio pensamiento, y que permite considerarla una "filósofa del martillo".

La crítica al monoteísmo se traduce filosóficamente en una crítica al Ser, al Uno y en definitiva a todas las nociones unificadores de la filosofía y en especial de la filosofía política. Al mismo tiempo, involucra una defensa empeńosa de la "pluralidad" como principio político y ontológico elemental. Visto desde la perspectiva del monoteísmo: El que de verdad Es, el Dios-Uno, es justamente el que no se revela, así nos aclara: "Contra el monoteísmo habla solamente el hecho de que Dios no se revela, es más, de que puede ser definido como el desconocido, que nunca se revela, mientras que los dioses en cualquier caso se revelan. Expresado de otro modo, por seguro que parezca que toda multiplicidad conocida por nosotros descansa en el uno oscuro como su fundamento, es igualmente seguro que eso uno permanece oscuro y que todo lo que se nos revela presupone pluralidad y se nos muestra en plural" (Arendt, DF: 101). Dios no es un quién porque no se revela. Lo que se revela, lo que aparece sólo aparece bajo la forma de la pluralidad. Lo que aparece está ontológicamente articulado desde la pluralidad, no tiene otra forma de aparecer.

Así, en el campo político la revelación de la identidad en el espacio público, es una revelación de los muchos, nunca la revelación de uno. La identidad, como revelación cifrada en acciones y discursos, se nos da sólo como la expresión en un crisol de voces y acciones, donde los otros, también

15 Recordemos que Arendt además de filosofía estudió teología y griego, que son sus dos especialidades menores. Además realizó su tesis doctoral en el pensamiento de San Agustín, o más bien en una interpretación contemporánea del mismo. 
son quienes.

Pero ¿cuál podría ser la forma de este enigma que es la identidad del quién revelado?, la forma de este enigma es sin duda en Arendt, un relato, la narración (story, narration). El enigma tiene la forma de un relato, esto quiere decir: tiene una forma, puede ser dicho o incluso representado, siempre que se le permita al enigma de la identidad guardar su secreto. Esto es lo que hace el relato. La identidad individual revelada en acciones y palabras es un secreto que el relato cuenta sin decir, sin descifrar, el relato guarda y cuenta al mismo tiempo el enigma de la identidad. Allí está el secreto del propio relato.

Se abre aquí el campo de la narración de historias, de las historias de vida, como única forma positiva de comprender la identidad que se muestra, como la única respuesta efectiva a la pregunta ¿Quién eres tú? (Arendt, 1993: 202).

No voy a entrar en la teoría de la narración, que a mi juicio es posible reconstruir a partir del parágrafo 25 de The Human Condition, y de algunos otros textos, como lo han hecho y de muy buena manera, Birulés, Kristeva, entre otros lectores de Arendt, y como bien marcan el camino los dos epígrafes de Dinesen ${ }^{16}$ y de Dante ${ }^{17}$ que abren el capítulo, (capítulo 5) que venimos analizando. La identidad del agente si puede ser dicha, con todas las precauciones que este decir tiene a la luz de lo ya analizado, puede serlo a través de una narración, que además otro enuncia en el espacio público y que al entrar en esa esfera, comienza a ser parte de las tramas de relatos que se recrean y se rehacen constantemente. Según los mismos epígrafes, el relato se sostiene existencialmente en el placer de relatar y en la capacidad de soportar el dolor, que marcan el privilegiado lugar existencial que constituye el relato, para hacernos posible vivir, de la mano del deseo y de la capacidad de traspasar el dolor, tal como resaltan Dante y Dinesen, respectivamente. Lo importante para nosotros ahora, es que como dice Forti, hay en estas reflexiones acerca de la identidad, la vida y la narración, una vía de desarrollo de una noción de la identidad en un claro horizonte postmetafísico.

16 "Todas las penas pueden soportarse si las ponemos en una historia o contamos una historia sobre ellas" (Isak Dinesen) (Arendt, 1993: 199).

17 "Porque en toda acción, lo que intenta principalmente el agente, ya actúe por necesidad natural o por libre voluntad, es explicar su propia imagen. De ahí que todo agente, en tanto hace se deleita en hacer; puesto que todo lo que apetece su ser, y puesto que en la acción el ser del agente está de algún modo ampliado, la delicia necesariamente sigue... Así, nada actúa a menos que al actuar haga patente su latente yo" (Dante) (Arendt, 1993: 199). 


\section{El quién de la pensadora Arendt}

Más que seguir el camino del análisis de la idea de identidad narrativa, que se encuentra esbozada en la obra de Arendt, reconduciremos estas ideas ya presentadas, acerca de la revelación del quién, a la propia biografía de Arendt. Al enigma concreto que esa identidad de judía-alemana, refugiada, mujer y pensadora nos propone. Sus apariciones públicas en los medios académicos fueron a lo largo de su vida cada vez más frecuentes, pero al parecer, como muestran algunas de sus cartas, nunca dejaron de incomodarla un poco. Cuestión que no parece tan evidente para quienes la escuchaban. Interesante en este sentido resulta el retrato que Mary McCarthy hace de la primera vez que vio a Arendt hablar en público, a mediados de los ańos 50" en Nueva York: "Me hizo recordar (dice McCarthy) lo que debe haber sido Sara Bernardt o la Berma de Proust, una espléndida diva del escenario... Lo que resultaba teatral de Hannah era una especie de poder espontáneo de ser acometida por una idea, una emoción, un presentimiento, de los cuales su cuerpo se convertía en vehículo, como en el caso de un actor. Y con unos ojos como platos, ¡Ach! (ante un cuadro, una obra algún hecho infamante) la situaba aparte del resto de nosotros, como una gran carga eléctrica"(Arendt y McCarthy, 1998: 261).

Pero su aparición en 'escena', estuvo desde su llegada a Norteamérica marcada por la escritura y la publicación, primero de artículos y luego de importantes obras. Arendt publicó y mucho, además de sus habituales presentaciones y entrevistas, incluso en radios y televisión. Quisiera concentrarse en dos de sus publicaciones más significativas en función del desarrollo de su 'aparecer' como pensadora política, intentando perfilar algunos ángulos del quién de la filósofa Arendt y la manera en que estas obras muestran momentos decisivos de su trayectoria como pensadora.

Su verdadera aparición pública, como pensadora política de relevancia, surge con la publicación de The Originis of Totalitarianism (1951). Una obra monumental, ambiciosa, desmesurada incluso, escrita en inglés, un idioma que ella no termina aún de dominar, publicado por una Arendt que aún era una perfecta desconocida, refugiada, emigrante judía, escapando de la Europa bajo la amenaza nazi. Escrita en la precariedad de su condición de refugiada, todavía bastante ajena a los medios intelectuales norteamericanos. Los Orígenes, es una obra no sólo monumental, sino expresión de un claro 
deseo de aparecer. De levantar la voz y tomar un lugar en la discusión pública acerca de un asunto central para ella a lo largo de toda su obra, como era la compresión del totalitarismo. Recordemos que el mismo término totalitarismo, no alcanza un uso y un conocimiento generalizado en Norteamérica sino hasta que Arendt publica su libro (Forti, 2008).

Para Young-Bruehl, la publicación de este libro marca un giro decisivo en la biografía de Arendt (Young-Bruhel, 1999). Muestra un deseo y una decisión de comparecer en el espacio público como un 'quién' que tiene un pensamiento y punto de vista completamente independientes. Es expresión así de una de las condiciones más propias de la personalidad de Arendt como pensadora, su decisión e independencia para fijar un punto de vista que, parafraseando la metáfora que ella utiliza para hablar de Lessing, se trata de un pensamiento que no requiere "barandas" apoyos, contextos culturales o sociales que la hagan sentirse cómoda para desarrollarse. (Young-Bruhe, 1999: 153 y ss). De hecho ya desde la publicación de Los Orígenes, las obras de Arendt, las más importantes, serán siempre recibidas polémicamente, aparecerán como un lugar de disputa que expone a la autora de una manera a veces feroz a la crítica y la polémica pública.

Pero antes de esta obra, decisiva en su biografía intelectual que marca un antes y un después en ella, hay otra obra que me gustaría rescatar y que tiene especial interés para el tema de la identidad de ese quién particular que fue la autora. Se trata de la extraña recopilación de cartas y esa especie de biografía que es Rahel Vanhagen vida una judía. Escrita primero en Alemania antes del año 1933, justo después de su tesis doctoral sobre el amor en San Agustín (1929). Este extraño libro, reconstruye parte de la biografía de la judía Rahel en su camino de asimilación, no del todo exitoso, a principios del siglo XIX. Mediante la recopilación de las cartas de Rahel, y su comentario, Arendt reconstruye el itinerario de estos judíos que se mueven entre la condición de asimilados y parias, en medio del ascenso del romanticismo alemán y del despliegue de sus principales figuras de la mano con el naciente nacionalismo y unificación de Alemania. Esta es una obra que ha fascinado a los estudiosos de Arendt por décadas, por su complejidad, por su extraño género (¿una biografía epistolar comentada?) sobre todo a las feministas. Pero es al mismo tiempo una obra agobiante: una gran cantidad de cartas de un personaje bastante estrambótico que expone sus sentimientos y romances (la mayoría imaginarios) y que van dejando una sensación de repetición y claustrofobia en la medida en que la historia, para ella siempre nueva, en realidad se repite. 
Siguiendo a Julia Kristeva, podemos ver en esta obra, no sólo el intento de presentar los textos de Rahel y sacar conclusiones sociológicas acerca de la situación de los judíos en la Europa de principios del XIX, sino un verdadero ajuste de cuentas con su propia condición de mujer judía, ajuste que le permitiría a Arendt despegarse de las sombras que dominaron su juventud y que eclipsaron en gran medida sus posibilidades de desarrollar una verdadera identidad y un verdadero pensar independiente.

Vale la pena anotar que es esta obra, sólo publicada en Nueva York años después, en 1958, mismo año de la publicación de The Human Condition, será muchos años después, la obra con la que Arendt reclamará como su tesis de habilitación, en su demanda al Estado Alemán, por la discriminación sufrida por su condición de mujer judía, y que la dejó fuera de la Universidad Alemana, después del año 1929, una vez aprobado con máxima distinción su doctorado. Juicio que será finalmente ganado por Arendt pocos años antes de su muerte, en 1971.

Siguiendo a Kristeva, podemos pensar en este primer discurso escrito, en esta obra como el trabajo que le permite ajustar su propia identidad, despejarla de los falsos modelos y acceder así a su propia condición de mujer y de pensadora. Se trata, como dice Kristeva, de “...atravesar la histeria de una (otra) mujer, no para evacuarla ni siquiera para analizarla, sino para transformarla en buen vivir. (...). A esta alquimia la llamamos sublimación (...) Gracias a la apropiación de una vida de una judía en pleno romanticismo, en adelante puede actuar y narrar otra vida de mujer y de teórica, pero desde el interior de una meditación política. (...) Después del autoanálisis con Rahel, Arendt se convirtió en la Berma del concepto ¡adiós a los pensadores profesionales!" (Kristeva: 2000, 234).

Deseo de ser independiente, posibilidad ser autora de la propia obra, sin ser su dueña ni su dominadora. Capacidad de utilizar las herramientas de la narración y del lenguaje, de la investigación y del pensamiento para esculpir una voz distinta, para cambiar el destino. Ajuste que le permite dar el paso desde una cierta juventud a la madurez.

Como ya he propuesto en otro sitio, la Rahel de Arendt puede ser pensada como una extraña y anómala novela de formación (Bildungsroman), que no propone y realiza un modelo a seguir, sino más bien desmonta un modelo: el modelo de la mujer definida desde el amor romántico, dicha por otro, que en realidad la recluye en una identidad pasiva, sin voz, sin registro, ni acción ni iniciativa. Mediante la repetición, una repetición que 
llega al aburrimiento de la biógrafa y del lector, se desarma este modelo romántico de la identidad hasta llevarlo a su disolución, mostrando como el amor romántico, exagerado hasta el paroxismo por Rahel, es en realidad un falso amor, la otra cara de la falta de amor al mundo.

Sería este ajuste de cuentas de Arendt como biógrafa de Rahel, el que preconiza la vitalidad y el compromiso de una mujer que piensa y escribe ya liberada de las ataduras de una feminidad agobiante, como la que respira en las cartas de Rahel. Entregándole a la propia Arendt elementos para otra femeneidad que logre ser una forma de profundizar y no evadir el amor del mundo, y con ello la visión política del mundo, cuestiones en las que probablemente descansa parte del enigma de su propio quién, como pensadora, y la atracción que ejerce su obra y su biografía sobre quienes leemos, (la leemos y nos leemos) en sus textos.

Referencias bibliográficas

Arendt Hannah (1981 [1978]), The Life of the Mind, Hartcourt, Florida. (1994 [1951], Origins of Totalitarianism, Harvest Book,

New

York.

(1998 [1958]), The Human Condition, University of Chica-

go,

Chicago.

(1993), La condición humana, Paidós, Barcelona.

(1990 [ 1963]), Hombres en tiempos de oscuridad.

Gedisa, Barcelona.

(2000 [1958]), Rahel Varnhagen. La vida de una mujer judia, Madrid, Lumen.

(2004 [1963]), Sobre la Revolución, Alianza, Madrid.'

Arendt Hannah y McCarthy Mary (1998), Entre amigas. Correspondencia entre Hannah Arendt y Mary McCarthy 1949-1975, Madrid: Lumen.

Aristóteles (2004), La Política, Akal, Madrid. 
mundo, Buenos Aires: Editorial Suramericana.

Forti Simona (2000), El Totalitarismo: trayectoria de una idea limite. Madrid: Herder.

(2001) Vida del espiritu y tiempo de la polis: Hannah Arendt entre filosofía y politica. Madrid: Cátedra.

Kristeva Julia (2000), El genio Femenino I: Hannah Arendt. Barcelona, Paidós. (2001), Life is narrative. Toronto, University of Toronto Press.

Merleau-Ponty Maurice (2004), La fenomenología de la percepción. México:

F.C.E. Young-Bruel, Elizabeth (1999), Subject to Biography, psychoanalysis, 